\title{
ORTUS - Gateway to University IS
}

Peteris Rudzajs ${ }^{1}$

${ }^{1}$ Riga Technical University, IT Department, 1 Kalku Street , Riga, Latvia, peteris.rudzajs@rtu.lv

\section{Keywords}

University portal, ORTUS, university IS environment, integration.

\section{EXTENDED ABSTRACT}

Each university engages in supporting its processes with ICT solutions. The decision about the choice and variety of the ICT is based on the history, the competence and the competitiveness of the university. This paper describes the core information systems (IS) in Riga Technical University, particularly, the university portal ORTUS that facilitates the access and the use of existing and new core information systems aimed to support the study, science and administrative processes. The way of organizing and integrating systems through ORTUS influences usage and overall acceptance of the provided services.

Currently, a variety of information systems (IS) are being used and maintained in Riga Technical University (RTU) to support study, science and administrative processes. Up till year 2007 RTU had different core IS widely distributed across university departments (see Figure 1 section A) with no integration between them, thus information exchange among IS and in the university in general was hindered. For example, a centralized Students Record Management System and decentralized elearning environments (instances of Moodle, Blackboard, and custom-made solutions) were used (if used at all) to support the study process; the subscribed academic resource databases in the library were accessible only from the library with different login names; only e-mail and "paper-based" tools were used for communication; systems for science, project management support and identity management were not available.

In 2007, the university portal ORTUS (source, rising - in Latin) was developed as a central source of information about studies and work and as a gateway to a variety of core IS (see Figure 1 section B). ORTUS facilitates the use and the access to information residing in different IS, thus improving the integration of different IS.

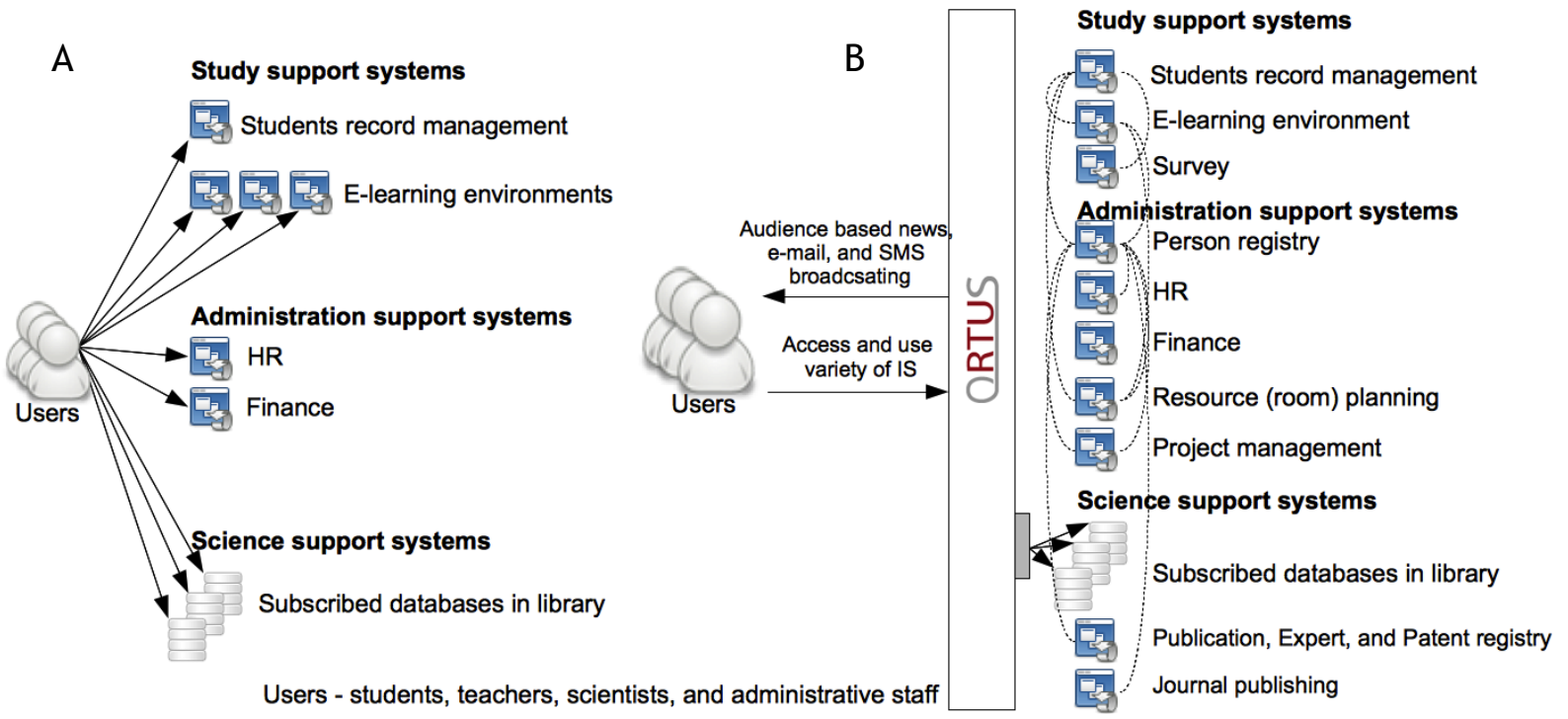

Figure 1. Access to university IS environment before and after introduction of ORTUS 
Due to introducing ORTUS in university everyday activities (study, administrative and scientific) as a means of gateway to integrated IS environment, the usage and acceptance of different IS have grown. ORTUS is the main reason for the raise of the usage of IS, particularly, the central e-learning environment, academic resource databases in library and communication means.

Central e-learning environment. With implementation of ORTUS, the existing and widely distributed e-learning environments were disregarded, and centrally maintained, supported and continuously upgraded environment had been introduced to support study processes (see Figure 1 section B). The usage of the e-learning environment is steadily increasing year by year - the average number of hits per month has increased from 250 thousands in 2008 to 1 million in 2012. It indicates that students benefit from the available learning resources and teachers are able to enrich the content to make it more useful. The e-learning environment has become a tool for an everyday use. E-learning courses with actual lists of students are generated automatically, so teachers don't have to worry about organizing the students' assignment to e-learning courses, they can focus on the content and quality of the course. Those are the benefits rising from the e-learning environment integration with the Central Person Registry, the Students Record Management System and the Resource Planning System. The provided training is an important means for improving quality of the study process at the university and it also encourages teachers and other university staff members to use the e-learning environment (Ivanovs, 2009), (Ivanovs, Citskovskis, Slaidiňš, \& Sukovskis, 2011).

Unified access to academic resource databases in the library. The workflow to access databases was simplified and unified. A user just signs in ORTUS and can freely access any of the databases subscribed by the library - there is no need to use different login names for each database, no need to be physically present in the library. ORTUS as a gateway provides unified access to all the databases. This improvement increased the usage of the academic databases, e.g., the count of user sessions for Science Direct database has increased from 9,200 in 2007 to 16,000 in 2012, for SpringerLink - from 960 to 2,600. This solution has facilitated the accessibility of the valuable academic resources, thus, supporting the excellence of the study and scientific activities at the university.

Communication means. Communication means have evolved at the university - e-mail and paperbased tools have been extended with more facilities that enable broadcasting of the news, e-mails and SMS designated to specific audiences. Audience specific solutions have provided possibility to distribute information to necessary audiences quickly. In case events should be urgently organized, e.g., unplanned guest lector speech about a specific topic, communication tools available in ORTUS provide quick communication with students from specific faculties and courses who could be particularly interested in the theme of the event. Thus, it is possible to gather necessary number of the students for the even in a short time. The centralized feature of distributing SMS is also a tool to provide important information to a particular user, e.g., to inform students of a particular course about teacher's unexpected absence one hour before the class.

When users visit ORTUS with their own goals (studies, research, administrative, etc.), we can ensure the customized information for each of them - surveys, news, notifications and other kinds of information acquired from different integrated systems. Thus we take advantage of ORTUS as the gateway to important areas of the university community. We understand and emphasize that the way of organizing and integrating systems influences the usage and overall acceptance of the services provided through ORTUS.

\section{REFERENCES}

Ivanovs, A. (2009). Internal Marketing: Search for Best Ways to Raise Usage of E-Learning System. Proceedings CD, International Conference on Education and New Learning Technologies (pp. 41084116).

Ivanovs, A., Citskovskis, U., Slaidiņš, I., \& Sukovskis, U. (2011). E-Learning at the Riga Technical University - Strategic Management of Innovation as a Way to Excellence. Proceedings of EADTU Annual Conference 2011 (pp. 218-231). 


\section{AUTHOR'S BIOGRAPHY}

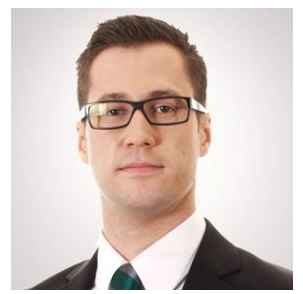

Peteris Rudzajs graduated Riga Technical University, Riga, Latvia, in 2010 with Master's degree in computer systems. Currently he is a 3rd year Doctoral student at the Institute of Applied Computer Systems, Riga Technical University. He works as a researcher at the Institute of Applied Computer Systems and as a head (previously - software engineer) of Information Systems Unit in Information Technology Department, Riga Technical University. He is a member of ACM and IEEE Computer Society associations. 